\title{
Idiopathic Sudden Sensorineural Hearing Loss Is Correlated with an Increased Risk of Stroke: An II-Year Nationwide Population-Based Study
}

\author{
Jae Sung Nam, Se Won Jeong, Su Jin Han, Jung Hyun Chang, and Hyun Seung Choi \\ Department of Otolaryngology-Head and Neck Surgery, National Health Insurance Service Ilsan Hospital, Goyang, Korea
}

\section{국민건강보험공단 표본 코호트 자료를 이용한 돌발성 난청과 뇌졸중 연관성 분석}

남재성 · 정세원 · 한수진 · 장정현 · 최현승

국민건강보험 일산병원 이비인후과학교실

Received November 30,2015

Revised January 5, 2016

Accepted January 9, 2016

Address for correspondence

Hyun Seung Choi, MD

Department of Otolaryngology-

Head and Neck Surgery,

National Health Insurance

Service Ilsan Hospital,

100 Ilsan-ro, Ilsandong-gu,

Goyang 10444, Korea

Tel +82-31-900-0972

Fax +82-31-900-0343

E-mail choihyunseung@gmail.com
Background and Objectives Sudden sensorineural hearing loss (S-SNHL) occurs abruptly, developing rapidly within 3 days. The criteria for the diagnosis of S-SNHL are idiopathic hearing loss of at least $30 \mathrm{~dB}$ over at least three serial test frequencies. This study estimated whether S-SNHL increases the risk of stroke using Korean National Health Insurance Service National Sample Cohort (NHIS-NSC 2002-2013) data.

Subjects and Method Among NHIS-NSC 2002-2013, we excluded the patients diagnosed as S-SNHL or stroke in 2002. The patients who were diagnosed and treated as S-SNHL $(n=2510)$ and the comparison group $(n=12550)$ extracted using propensity score matching were enrolled. During an 11-year follow-up period until December 2013, the incidence of stroke among two groups was analyzed and the result was adjusted for the impact of comorbidities such as hypertension, diabetes, and chronic kidney disease with Cox proportional hazard regression. Results According to our data, $10.8 \%$ of S-SNHL patients (among 2510) and $7.8 \%$ of the comparison group (among 12550) had strokes. Stroke incidence was reported higher in patients with history of S-SNHL compared to the comparison group [hazard (HR), 1.15; 95\% confidence interval (CI), 1.01-1.32] followed by patients with hypertension (HR, 2.51; 95\% CI, 2.22-2.84), diabetes mellitus (HR, 1.62; 95\% CI, 1.43-1.85). In terms of the type of strokes, S-SNHL increased the risk of ischemic stroke (HR, 1.18; 95\% CI, 1.02-1.37).

Conclusion S-SNHL appeared to be associated with an increased risk of developing stroke after adjusting for other risk factors.

Korean J Otorhinolaryngol-Head Neck Surg 2016;59(5):353-60

Key Words Brain ischemia $\cdot$ Intracranial hemorrhages $\cdot$ Stroke $\cdot$ Sudden hearing loss.

\section{서 론}

돌발성 난청은 이비인후과적 응급 질환으로 환자들에게는 공포스러운 경험이다. 일반적으로 3일 이내 갑자기 발생한 난 청으로 3 개의 연속된 주파수에서 $30 \mathrm{~dB}$ 이상의 청력 감소가 있을 때 진단하게 된다. ${ }^{1)}$ 가능성이 있는 원인 질환으로 바이러 스 감염, 혈관 장애, 종양, 외상, 이독성 약제의 사용, 자가면역 질환, 선천적 발달 이상과 정신과적 질환 등이 있지만, 여러 가
지 검사를 통해 원인을 밝힐 수 있는 경우는 전체의 $5 \%$ 미만 으로 보고되고 있다. ${ }^{2}$ 최근 영상의학 검사 장비의 발달로 혈 관 질환과의 연관성이 증명되고 있으며, 돌발성 난청이 뇌졸중 의 전조 증상으로 나타날 수 있다는 연구들이 발표되면서 그 관심이 커지고 있다.,4) 또한 정보의 저장과 처리 기술의 발달, 정부의 정보 공개 방침의 변화로 전국민의 건강보험 자료의 활용이 가능해졌다. 본 연구에서는 우리나라 건강보험 자료를 활용하여 실제로 돌발성 난청으로 진단받은 사람이 뇌졸중의 
위험도가 커지는지 알아보고자 하였다.

\section{대상 및 방법}

본 연구는 국민건강보험공단 표본 코호트(NHIS-NSC 2002-2013) 자료를 이용하였고, 이는 국민건강보험공단의 윤 리위원회로부터 승인된 자료이며, 연구의 진행은 본원 윤리위 원회의 심의를 받은 후 이루어졌다.

\section{연구 데이터 베이스}

우리나라 건강보험제도는 전 국민을 대상으로 법에 의해 가 입이 강제되기 때문에 전 국민의 의료 기관 및 약국 사용에 관 련된 모든 자료가 국민건강보험공단에 저장, 관리되고 있다. 2013년 기준으로 우리나라 국민 51448491명(남자: 25780383명, 여자: 25668348명) 중 97.1\%가 건강보험제도에 가입되고 있는 것으로 알려져 있다. ${ }^{5}$ 국민건강보험공단 자료에는 환자의 거주 지, 소득 분위, 가족 관계와 같은 사회인구통계학적 자료, 외래, 입원 진료 기록, 약국 청구자료 등이 모두 포함되어 있다. 전체 자료는 개인정보의 보호 문제나 물리적 데이터의 크기 등의 이 유로 연구자들이 쉽게 접근성을 확보하기 힘들기 때문에 원 자 료(raw data)에 준하는 결과물을 얻을 수 있고, 개인정보를 노출 시키지 않는 연구용 표본자료가 필요하다. 본 연구는 국민건강 보험공단 자료의 대표성을 만족하는 $2 \%$ 의 표본추출자료인 표 본 코호트 자료를 기반으로 이루어졌다. 표본 코호트 자료는 국 민건강보험 공단 빅데이터 운영실에서 2002년 인구특성과 소득 분위를 고려하여 비례 배분(proportional allocation)에 의한 층 화임의추출(stratified random sampling) 방법으로 이루어졌다. 2002년 전체 인구의 2.2\%(1025340명)를 표본으로 추출하였고 이후 사망이나 이민 등의 이유로 코호트에서 제외된 숫자는 그 해 태어난 신생아로 채웠으며, 개인정보보호를 위해 주민등록 번호를 삭제하고 8 자리의 개인식별번호를 부여하여 관리된다.

\section{연구 대상}

이번 연구는 2002년에서 2013년까지 12년간 국민건강보험 공단 표본 코호트 자료(NHIS-2015-2-089)를 이용하여 이루 어졌으며 이 기간 동안 국내에서 시행된 비급여 진료를 제외 한 모든 청구 자료를 참고하였다. 표본 코호트 자료의 진단명 은 국제질병분류(ICD-10)를 수정한 한국표준질병사인분류 (KCD-6)에 기초하고 있다. 돌발성 특발성 청력 소실(H912) 청구 코드에 해당하는 환자를 연구 대상으로 하였고, 연구 기 간 동안 처음 진단된 환자들만을 대상으로 하기 위해 2002년 1년 동안 돌발성 난청으로 외래진료를 시행받았거나 입원했던 환자들은 제외하였다. 2003년 1월부터 2005년 12월까지 3년

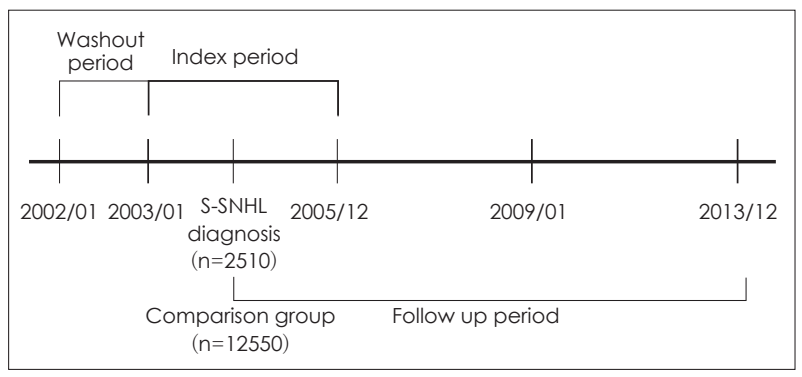

Fig. 1. Definition of object. Among NHIS-NSC 2002-2013 data $(n=1025340)$, the patients treated as S-SNHL in 2002 for a year were excluded (washout period). The patients diagnosed as SSNHL $(n=2510)$ from January 2003 to December 2005 for 3 years (index period) and the comparison group $(n=12550)$ extracted using propensity score matching were enrolled. During an 11-year follow-up period the risk of strokes between two groups were analysed. NHIS-NSC: National Health Insurance Service National Sample Cohort, S-SNHL: sudden sensorineural hearing loss.

동안 돌발성 난청으로 진료받고 공단으로 청구된 환자를 실험 군으로 하였으며 각각 774 명, 860명, 876명이었다. 비교분석을 위해 연령, 성별, 거주 지역, 가계 소득 등을 고려하여 대조군 을 선정하였으며, 실험군과 비슷한 성향을 가진 환자들로 성 향 점수 매칭(propensity Score Matching)방법을 통해 1:5로 추출하였다. 대조군은 2003년 3870명, 2004년 4300명, 2005년 4380명으로 총 12550명이 추출되었으며, 2013년 12월까지 모 든 공단 청구 내용을 통해 자료를 분석하였다(Fig. 1). 뇌졸중 은 $\mathrm{KCD}-6$ 에서 $\mathrm{I} 60-63$ 에 해당되는 청구 코드로 확인하였고, 허혈성 뇌졸중(I63)과 출혈성 뇌졸중(I60-62)을 구분하였다. 같은 이유로 2002년 1월에서 12월까지 1년 동안 뇌졸중으로 진료를 받은 환자는 연구 대상에서 제외하였다. 기타 뇌졸중과 의 연관성이 있다고 알려진 고혈압(I10-15), 당뇨(E10-14), 만성 신장 질환(N18) 등도 같은 방법으로 분석에 포함하였다.

\section{통 계}

두 군과의 차이를 보기 위해 chi-square 분석을 이용하였 고, 뇌졸중의 위험도 분석을 위해서 단변량 $\mathrm{Cox}$ 비례위험모형 (univariate Cox proportional hazard regression), 여러 질환에 같이 이완되어 있거나 사회인구학적 특성을 보정한 다변량 Cox 비례위험모형(multivariate Cox proportional hazard regression)을 사용하였다. 통계학적 유의성 확인은 0.05 로 하였 으며, 통계 패키지는 윈도우용 SAS System, version 9.4(SAS Inc., Cary, NC, USA)를 이용하였다.

\section{결 과}

\section{돌발성 난청군과 대조군의 성격}

표본 코호트 자료에 포함된 1025340명에서 2003년 1월부터 2005년 12월까지 돌발성 난청으로 진단되어 진료를 받은 환 
자는 2510 명이었고, 약 $10.8 \%(271$ 명)에서 추적관찰 기간 중 뇌졸중이 발생하였다(Table 1). $1.6 \%$ (39명)가 출혈성 뇌졸중, $9.2 \%(232$ 명)가 허혈성 뇌졸중에 이환되었으며, 대조군은 같은 기간 12550 명 중 $7.8 \%(975$ 명)가 뇌졸중으로 진단받았고 각각
$1.4 \%(176$ 명), 6.4\%(799명)로 나타나 돌발성 난청군이 뇌졸중 에 이환되는 비율이 더 높고 특히 허혈성 뇌졸중 발생률이 높 은 것으로 보였다. 고혈압, 당뇨, 만성 신장 질환을 가진 환자 는 돌발성 난청군에서 모두 대조군에 비해 유의하게 많았다.

Table 1. Characteristics of the sudden sensorineural hearing loss $(\mathrm{S}-\mathrm{SNHL})$ group $(\mathrm{n}=2510)$ and the study population comparison group $(n=12550)$

\begin{tabular}{|c|c|c|c|}
\hline Variable & S-SNHL group no. (\%) & Comparison group no. (\%) & $p$ value \\
\hline Stroke & & & $<0.001$ \\
\hline No event & $2239(89.2)$ & $11575(92.2)$ & \\
\hline Event & $271(10.8)$ & $975(7.8)$ & \\
\hline \multicolumn{4}{|l|}{ Stroke subtype } \\
\hline No event & $2239(89.2)$ & 11575 (92.2) & \\
\hline Hemorrhagic & $39(1.6)$ & $176(1.4)$ & \\
\hline Ischemic & $232(9.2)$ & $799(6.4)$ & \\
\hline Hypertension & & & $<0.001$ \\
\hline No & $1854(73.9)$ & $10689(85.2)$ & \\
\hline Yes & $656(26.1)$ & $1861(14.8)$ & \\
\hline Diabetes Mellitus & & & $<0.001$ \\
\hline No & $1997(79.6)$ & $11355(90.5)$ & \\
\hline Yes & $513(20.4)$ & $1195(9.5)$ & \\
\hline Chronic kidney disease & & & $<0.001$ \\
\hline No & $2481(98.4)$ & $12519(99.8)$ & \\
\hline Yes & $29(1.6)$ & $31(0.2)$ & \\
\hline \multicolumn{4}{|l|}{ Variables included in matching } \\
\hline \multicolumn{4}{|l|}{ Year of S-SNHL diagnosis } \\
\hline 2003 & $774(30.8)$ & $3870(30.8)$ & \\
\hline 2004 & $860(34.3)$ & $4300(34.3)$ & \\
\hline 2005 & $876(34.9)$ & $4380(34.9)$ & \\
\hline Age group & & & 0.998 \\
\hline$<20$ & $252(10.0)$ & $1260(10.0)$ & \\
\hline $20-29$ & $264(10.5)$ & $1320(10.5)$ & \\
\hline $30-39$ & $407(16.2)$ & $2035(16.2)$ & \\
\hline $40-49$ & $482(19.2)$ & $2410(19.2)$ & \\
\hline $50-59$ & $494(19.7)$ & $2467(19.6)$ & \\
\hline $60-69$ & $432(17.2)$ & $2165(17.3)$ & \\
\hline$>70$ & $179(7.1)$ & $893(7.1)$ & \\
\hline Gender & & & 0.965 \\
\hline Male & $1149(45.8)$ & $5752(45.8)$ & \\
\hline Female & $1361(54.2)$ & $6798(54.2)$ & \\
\hline Residential area & & & 0.899 \\
\hline Seoul & $593(23.6)$ & $2975(23.7)$ & \\
\hline Large city & $580(23.1)$ & $2901(23.1)$ & \\
\hline Small city & $1111(44.3)$ & $5556(44.3)$ & \\
\hline Rural & $226(9.0)$ & $1118(8.9)$ & \\
\hline Household income relative to the median & & & 0.970 \\
\hline$<20 \%$ & $288(11.5)$ & 1449 (11.5) & \\
\hline $20-40 \%$ & $347(13.8)$ & 1731 (13.8) & \\
\hline $40-60 \%$ & 439 (17.5) & 2195 (17.5) & \\
\hline $60-80 \%$ & $587(23.4)$ & 2925 (23.3) & \\
\hline$>80 \%$ & 849 (33.8) & 4250 (33.9) & \\
\hline
\end{tabular}


연령별로 보면 20 세 이하에서 전체의 $10 \%$ 정도를 차지하였고 40,50 대 환자가 각각 $19.2 \%$ (482명), $19.7 \%$ (494명)로 가장 많 은 비중을 차지하고 있었다. 성별로 보면 남자가 45.8\%(1149 명), 여자가 54.2\%(1361명)로 여자에서 더 많이 진단되었고, 거 주 지역은 서울이나 대도시에 비해 중소도시지역의 환자가 $44.3 \%(1111$ 명)로 가장 많았다. 가계 소득에 따라 구분해보았 을 때, 하위 $20 \%$ 이하의 환자가 가장 적고(11.5\%), 상위 $80 \%$ 이상의 환자가 $33.8 \%$ 로 가장 많았으며 소득이 높을수록 환자 가 많아지는 경향을 보였다. 대조군의 추출은 2003년에서
2005년까지 3년 동안 1:5 비율로 성향 점수 매칭 방법을 통해 이루어졌으며, 진단받은 시기와 연령, 성별, 거주 지역, 소득분 위 모두에서 실험군과 차이를 보이지 않았다.

\section{각 변수에 따른 뇌졸중의 위험도}

여러 변수에 따른 뇌졸중의 위험도를 $\operatorname{Cox}$ 비례위험모형을 사용하여 분석한 결과, 돌발성 난청군에서 연령, 성별, 거주 지 역, 가계 소득, 다른 이환 질환(고혈압, 당뇨, 만성 신장 질환) 의 영향을 보정한 이후에도 뇌졸중 발생 위험이 더 큰 것으

Table 2. Univariate and multivariate Cox regression analyses of overall hazard ratio related to stroke during an eleven-year follow-up period

\begin{tabular}{|c|c|c|c|c|}
\hline \multirow{2}{*}{ Variable } & Univariate & \multirow{2}{*}{ p-value } & Multivariate & \multirow{2}{*}{$p$-value } \\
\hline & $\mathrm{HR}(95 \% \mathrm{Cl})$ & & $\mathrm{HR}(95 \% \mathrm{Cl})$ & \\
\hline \multicolumn{5}{|l|}{ Group } \\
\hline Comparison group & 1 & & 1 & \\
\hline S-SNHL group & $1.44(1.26-1.65)$ & $<0.0001^{*}$ & $1.153(1.01-1.32)$ & $0.0418^{*}$ \\
\hline \multicolumn{5}{|l|}{ Gender } \\
\hline Male & 1 & & 1 & \\
\hline Female & $0.94(0.84-1.05)$ & 0.2716 & $0.81(0.72-0.90)$ & $0.0002^{*}$ \\
\hline \multicolumn{5}{|l|}{ Age } \\
\hline$<20$ & $0.43(0.15-1.23)$ & 0.1164 & $0.45(0.16-1.27)$ & 0.1297 \\
\hline $20-29$ & 1 & & 1 & \\
\hline $30-39$ & $2.22(1.17-4.23)$ & $0.0149 *$ & $2.15(1.13-4.08)$ & $0.0202^{*}$ \\
\hline $40-49$ & $6.59(3.65-11.87)$ & $<0.0001^{*}$ & $5.50(3.05-9.93)$ & $<0.0001^{*}$ \\
\hline $50-59$ & $13.53(7.60-24.11)$ & $<0.0001^{*}$ & $9.33(5.22-16.66)$ & $<0.0001^{*}$ \\
\hline $60-69$ & $25.92(14.61-45.96)$ & $<0.0001^{*}$ & $15.13(8.49-26.97)$ & $<0.0001^{*}$ \\
\hline$>70$ & $41.97(23.56-74.77)$ & $<0.0001^{*}$ & $24.86(13.88-44.58)$ & $<0.0001^{*}$ \\
\hline \multicolumn{5}{|l|}{ Household income } \\
\hline $0-20 \%$ & 1 & & 1 & \\
\hline $20-40 \%$ & $0.75(0.61-0.93)$ & $0.0075^{*}$ & $1.05(0.85-1.30)$ & 0.642 \\
\hline $40-60 \%$ & $0.70(0.57-0.85)$ & $0.0005^{*}$ & $1.02(0.83-1.25)$ & 0.8868 \\
\hline $60-80 \%$ & $0.73(0.60-0.88)$ & $0.0008^{*}$ & $1.00(0.82-1.21)$ & 0.9596 \\
\hline $80-100 \%$ & $0.83(0.70-0.99)$ & $0.0369^{*}$ & $0.96(0.81-1.15)$ & 0.6628 \\
\hline \multicolumn{5}{|l|}{ Residential area } \\
\hline Seoul & 1 & & 1 & \\
\hline Large city & $0.98(0.83-1.16)$ & 0.7911 & $1.06(0.89-1.25)$ & 0.54 \\
\hline Small city & $1.07(0.92-1.23)$ & 0.3729 & $1.10(0.95-1.27)$ & 0.1982 \\
\hline Rural & $1.50(1.23-1.83)$ & $<0.0001^{*}$ & $1.25(1.02-1.52)$ & $0.0304^{*}$ \\
\hline \multicolumn{5}{|l|}{ Diabetes } \\
\hline No & 1 & & 1 & \\
\hline \multicolumn{5}{|l|}{ Mellitus } \\
\hline Yes & $3.92(3.48-4.42)$ & $<0.0001^{*}$ & $1.62(1.43-1.85)$ & $<0.0001^{*}$ \\
\hline \multicolumn{5}{|l|}{ Hypertension } \\
\hline No & 1 & & 1 & \\
\hline Yes & $5.79(5.18-6.47)$ & $<0.0001^{*}$ & $2.51(2.22-2.84)$ & $<0.0001^{*}$ \\
\hline \multicolumn{5}{|l|}{ Chronic kidney disease } \\
\hline No & 1 & & 1 & \\
\hline Yes & $2.60(1.47-4.58)$ & $0.001^{*}$ & $0.73(0.41-1.30)$ & 0.2827 \\
\hline
\end{tabular}

*significant $p$ values. HR: hazard ratio, Cl: confidence interval, S-SNHL: sudden sensorineural hearing loss 
로 나타났다[hazard ratio(HR), 1.15; 95\% confidence interval (CI), 1.01-1.32](Table 2), 여자에서 남자에 비해 위험도가 낮 았으며, 나이가 많을수록 위험도는 높아져 20대 환자에 비해 60 대는 15 배, 70 대는 24 배 이상 뇌졸중 위험도가 높아졌다. 가계 소득은 뇌졸중의 위험도와 관계없었지만 거주 지역이 시골인 경우는 뇌졸중 위험도가 높게 나타났다(HR, 1.25; $95 \% \mathrm{CI}, 1.02-1.52)$. 만성 신장 질환( $\mathrm{HR}, 0.73$; 95\% CI, 0.141.30)을 제외한 고혈압(HR, 2.51; 95\% CI, 2.22-2.84), 당뇨 (HR, $1.62 ; 95 \%$ CI, 1.43-1.85)를 가진 환자는 뇌졸중의 위험 도가 높아졌다.

\section{뇌졸중의 유형에 따른 위험도}

뇌졸중을 허혈성과 출혈성으로 나누어 보았을 때, 돌발성 난 청은 연령, 성별, 고혈압, 당뇨, 만성 신장 질환과 같은 다른 변 수를 보정한 다변량 분석한 결과에서 출혈성 뇌졸중의 위험도 를 높이지 않는 것으로 나타났고(HR, 1.01; 95\% CI, 0.71-1.44), 허혈성 뇌졸중의 위험도를 높이는 것으로 보였다(HR, 1.18 ; 95\% CI, 1.02-1.37)(Table 3). 성별로는 두 유형 모두에서 여자 의 위험도가 낮게 나타났으며, 연령에 따른 위험도가 가장 많 이 증가하는 것으로 나타났다. 가계 소득과 거주 지역에 따른 위험도도 발견되지 않았으며 고혈압은 뇌졸중의 두 유형 모두

Table 3. Multivariate Cox regression analyses of overall hazard ratio according to stroke subtype during an eleven-year follow-up period

\begin{tabular}{|c|c|c|c|c|}
\hline \multirow{2}{*}{ Variable } & Hemorrhagic stroke & \multirow{2}{*}{$\mathrm{p}$-value } & Ischemic stroke & \multirow{2}{*}{ p-value } \\
\hline & $\mathrm{HR}(95 \% \mathrm{Cl})$ & & $\mathrm{HR}(95 \% \mathrm{Cl})$ & \\
\hline \multicolumn{5}{|l|}{ Group } \\
\hline Comparison group & 1 & & 1 & \\
\hline S-SNHL group & $1.01(0.71-1.44)$ & 0.9393 & $1.18(1.02-1.37)$ & $0.0273^{*}$ \\
\hline \multicolumn{5}{|l|}{ Gender } \\
\hline Male & 1 & & 1 & \\
\hline Female & $0.69(0.53-0.91)$ & $0.008^{*}$ & $0.82(0.73-0.93)$ & $0.0019^{*}$ \\
\hline \multicolumn{5}{|l|}{ Age } \\
\hline$<20$ & $1.87(0.46-7.83)$ & 0.933 & - & 0.9172 \\
\hline $20-29$ & 1 & & 1 & \\
\hline $30-39$ & $3.96(1.17-13.47)$ & $0.0275^{*}$ & $1.59(0.74-3.44)$ & 0.2374 \\
\hline $40-49$ & $6.68(2.05-21.72)$ & $0.0016^{*}$ & $5.29(2.67-10.46)$ & $<0.0001^{*}$ \\
\hline $50-59$ & $8.07(2.50-26.05)$ & $0.0005^{*}$ & $9.95(5.10-19.42)$ & $<0.0001^{*}$ \\
\hline $60-69$ & $11.66(3.62-37.49)$ & $<0.0001^{*}$ & $16.62(8.54-32.34)$ & $<0.0001^{*}$ \\
\hline$>70$ & $16.95(5.13-56.01)$ & $<0.0001^{*}$ & $28.10(14.36-54.99)$ & $<0.0001^{*}$ \\
\hline \multicolumn{5}{|l|}{ Household income } \\
\hline $0-20 \%$ & 1 & & 1 & \\
\hline $20-40 \%$ & $1.15(0.70-1.87)$ & 0.5834 & $1.03(0.81-1.31)$ & 0.8095 \\
\hline $40-60 \%$ & $1.08(0.67-1.73)$ & 0.7531 & $1.00(0.80-1.26)$ & 0.9926 \\
\hline $60-80 \%$ & $0.81(0.51-1.30)$ & 0.3824 & $1.04(0.84-1.28)$ & 0.7315 \\
\hline $80-100 \%$ & $0.79(0.51-1.22)$ & 0.2905 & $1.00(0.82-1.21)$ & 0.9929 \\
\hline \multicolumn{5}{|l|}{ Residence } \\
\hline Seoul & 1 & & 1 & \\
\hline Large city & $1.26(0.83-1.91)$ & 0.2838 & $1.02(0.85-1.23)$ & 0.8234 \\
\hline Small city & $1.25(0.86-1.81)$ & 0.2424 & $1.08(0.92-1.27)$ & 0.3532 \\
\hline Rural & $1.53(0.94-2.50)$ & 0.0858 & $1.22(0.98-1.52)$ & 0.0815 \\
\hline \multicolumn{5}{|l|}{ Diabetes } \\
\hline No & 1 & & 1 & \\
\hline \multicolumn{5}{|l|}{ Mellitus } \\
\hline Yes & $1.14(0.79-1.62)$ & 0.4878 & $1.74(1.51-2.00)$ & $<0.0001^{*}$ \\
\hline \multicolumn{5}{|l|}{ Hypertension } \\
\hline No & 1 & & 1 & \\
\hline Yes & $2.28(1.67-3.10)$ & $<0.0001^{*}$ & $2.60(2.27-2.98)$ & $<0.0001^{*}$ \\
\hline \multicolumn{5}{|l|}{ Chronic kidney disease } \\
\hline No & 1 & & 1 & \\
\hline Yes & $1.45(0.45-4.61)$ & 0.5327 & $0.64(0.33-1.25)$ & 0.1904 \\
\hline
\end{tabular}

*significant $p$ values. HR: hazard ratio, Cl: confidence interval, S-SNHL: sudden sensorineural hearing loss 
에서 위험도를 2 배 이상 높였으며, 당뇨의 경우 출혈성 뇌졸중 의 위험도는 높이지 않았고(HR, $1.14 ; 95 \%$ CI, 0.79-1.62) 허 혈성 뇌졸중의 위험도만 높이는 것으로 나타났다(HR, 1.74; 95\% CI, 1.51-2.00).

\section{돌발성 난청으로 외래 진료만 시행한 환자 분석}

돌발성 난청으로 입원하여 치료받지 않고 외래 진료만 시행 받은 군은 대조군에 비해 출혈성 뇌졸중의 위험도는 오히려 낮은 것으로 분석되었고( $\mathrm{HR}, 0.68 ; 95 \% \mathrm{CI}, 0.52-0.90)$, 허혈성
뇌졸중의 위험도는 커지는 것으로 나타났다(HR, 1.23; 95\% CI, 1.03-1.48)(Table 4). 성별, 가계 소득, 거주 지역, 만성 신장 질환에 따른 위험도 차이는 없었으며, 고혈압, 당뇨에 이환되 어 있을 때는 뇌졸중의 두 유형 모두에서 위험도가 유의미하 게 높아지는 것으로 분석되었다.

\section{고 찰}

돌발성 난청은 95\%에서 그 원인 질환을 규명할 수 없는 것

Table 4. Multivariate Cox regression analyses of overall hazard ratio in OPD-based patients during an eleven-year follow-up period

\begin{tabular}{|c|c|c|c|c|}
\hline \multirow{2}{*}{ Variable } & Hemorrhagic stroke & \multirow{2}{*}{$p$-value } & Ischemic stroke & \multirow{2}{*}{$p$-value } \\
\hline & $\mathrm{HR}(95 \% \mathrm{Cl})$ & & $\mathrm{HR}(95 \% \mathrm{Cl})$ & \\
\hline \multicolumn{5}{|l|}{ Group } \\
\hline Comparison group & 1 & & 1 & \\
\hline S-SNHL group & $0.68(0.52-0.90)$ & $0.0063^{*}$ & $1.23(1.03-1.48)$ & $0.0235^{*}$ \\
\hline \multicolumn{5}{|l|}{ Gender } \\
\hline Male & 1 & & 1 & \\
\hline Female & $0.88(0.71-1.10)$ & 0.2617 & $0.94(0.80-1.09)$ & 0.3839 \\
\hline \multicolumn{5}{|l|}{ Age } \\
\hline$<20$ & - & & - & \\
\hline $20-29$ & 1 & & 1 & \\
\hline $30-39$ & $1.21(0.22-6.60)$ & 0.8282 & $1.72(0.72-4.10)$ & 0.22 \\
\hline $40-49$ & $6.41(1.51-27.17)$ & $0.0116^{*}$ & $5.07(2.34-11.01)$ & $<0.0001^{*}$ \\
\hline $50-59$ & $10.74(2.62-43.99)$ & $0.001 *$ & $8.60(4.02-18.40)$ & $<0.0001^{*}$ \\
\hline $60-69$ & $13.83(3.39-56.40)$ & $0.0002^{*}$ & $14.17(6.64-30.22)$ & $<0.0001^{*}$ \\
\hline$>70$ & $20.69(5.06-84.67)$ & $<0.0001^{*}$ & $20.33(9.44-43.80)$ & $<0.0001^{*}$ \\
\hline \multicolumn{5}{|c|}{ Household income income } \\
\hline $0-20 \%$ & 1 & & 1 & \\
\hline $20-40 \%$ & $0.94(0.60-1.45)$ & 0.7728 & $0.94(0.70-1.27)$ & 0.4794 \\
\hline $40-60 \%$ & $0.90(0.61-1.35)$ & 0.6196 & $0.95(0.72-1.27)$ & 0.9894 \\
\hline $60-80 \%$ & $1.18(0.82-1.68)$ & 0.3782 & $1.04(0.80-1.36)$ & 0.8844 \\
\hline $80-100 \%$ & $0.85(0.61-1.19)$ & 0.3474 & $1.09(0.86-1.39)$ & 0.7373 \\
\hline \multicolumn{5}{|l|}{ Residence } \\
\hline Seoul & 1 & & 1 & \\
\hline Large city & $1.05(0.75-1.45)$ & 0.7832 & $0.90(0.71-1.13)$ & 0.3662 \\
\hline Small city & $0.85(0.64-1.15)$ & 0.2943 & $1.05(0.87-1.28)$ & 0.5869 \\
\hline Rural & $1.08(0.72-1.63)$ & 0.6986 & $1.26(0.97-1.64)$ & 0.0868 \\
\hline \multicolumn{5}{|l|}{ Diabetes } \\
\hline No & 1 & & 1 & \\
\hline \multicolumn{5}{|l|}{ Mellitus } \\
\hline Yes & $1.59(1.25-2.02)$ & $0.0002^{*}$ & $1.69(1.42-2.00)$ & $<0.0001^{*}$ \\
\hline \multicolumn{5}{|l|}{ Hypertension } \\
\hline No & 1 & & 1 & \\
\hline Yes & $1.52(1.22-1.91)$ & $0.0003^{*}$ & $3.01(2.55-3.55)$ & $<0.0001^{*}$ \\
\hline \multicolumn{5}{|l|}{ Chronic kidney disease } \\
\hline No & 1 & & 1 & \\
\hline Yes & $1.54(0.55-4.28)$ & 0.4128 & $0.51(0.21-1.23)$ & 0.1342 \\
\hline
\end{tabular}


으로 알려져 있으며, 위험인자로는 심혈관계 이상, 흡연, 과도 한 음주, 혈액 응고와 관련된 유전자 이상 등이 알려져 있다.) 최근에는 만성 치주염을 가지고 있는 환자에서 돌발성 난청이 $40 \%$ 이상 더 발생한다는 보고도 있었다. ${ }^{7)}$ 돌발성 난청 환자의 $65 \%$ 가 발병 전에 상기도 감염의 병력이 있어 바이러스 감염 과 관련성이 높지만 바이러스 항체의 혈청학적 방법을 통한 진단은 유용하지 않은 것으로 알려져 있다. 돌발성 난청의 연 중 발생 분포와 기후 인자 사이에 관계가 있다는 보고도 있지 만 인과 관계가 아직 불분명한 상태이다. ${ }^{8)}$ 하지만 대만의 코 호트 연구에서는 헤르페스 바이러스 감염 환자 30만 명을 발 병 이후 2 개월간 관찰해보았을 때 돌발성 난청 발생률이 일반 인과 차이가 없다는 보고도 있다."

국내외에 뇌졸중과 관련하여 발생한 돌발성 난청의 사례들 이 많고 전하소뇌동맥의 상태가 돌발성 난청과 임상적인 관계 가 있다고 하며,10,11) 돌발성 난청의 위험인자와 심혈관 질환의 위험인자가 상당 부분 유사하다는 결과는 돌발성 난청의 원인 질환으로 혈관 장애를 생각하는 합리적인 추론이 되고 있 다. ${ }^{12)}$ 특히 최근에는 양측으로 발생한 돌발성 난청 환자에서 척추동맥의 협착이 발견되어 스텐트 시술을 받았고 이후 점차 적인 청력 회복을 보였다고 보고도 있었다. ${ }^{13)} \mathrm{Huang}$ 등 ${ }^{14}$ 과 Sauvaget 등 ${ }^{15}$ 의 연구에 따르면 뇌졸중의 $1.2 \sim 1.4 \%$ 가 돌발성 난청으로 시작된다고 한다. $\operatorname{Lin}$ 등히은 대만의 건강보험 데이 터를 이용해 분석한 결과 돌발성 난청 발생 후 5 년 내에 뇌졸 중이 $12.7 \%$ 에서 발생하며 이는 일반인의 뇌졸중 발생률보다 높다고 보고하였다. 또한 높은 에너지 소모와 부족한 측부 순 환으로 인해 내이의 기능이 일시적인 허혈에도 민감한 특성을 가지고 있어 고지혈증, 동맥경화증과 같은 순환기 장애를 가 진 환자에서 돌발성 난청은 전하 소뇌 동맥 경색의 전조 증상 으로 나타날 수 있다고 하였다. ${ }^{17)}$ 하지만 한 의료기관에서 돌 발성 난청으로 진단받은 349 명의 추적관찰 결과에서는 일반 인들과 뇌졸중의 발생률에서 차이를 보이지 않았다. ${ }^{18)}$

최근 전 국민을 대상으로 하는 의료 정보 이용이 가능해지 면서 전 세계적으로 전향적 코호트 연구(prospective Cohort study)나 횡단적 단면 연구(cross-sectional study)가 활발히 이루어지고 있다. ${ }^{16,19)}$ 특히 돌발성 난청과 같은 원인 불명의 질환 연구에 있어서 빅데이터의 분석을 통한 가설의 설정은 중요한 연구 방법론으로 떠오르고 있다. 대만에서 건강보험 자료를 이용하여 1423 명의 돌발성 난청으로 입원했던 환자와 다른 기저 질환이 없는 충수절제술 환자 5692 명의 5 년간의 코호트 자료를 분석한 결과, 돌발성 난청 환자군에서 뇌졸중 위험도가 1.64 배 높았다는 보고가 있었다. ${ }^{16}$

본 연구는 국민건강보험공단 표본 코호트 자료를 활용하여 돌발성 난청 환자가 성향이 비슷한 대조군에 비해 뇌졸중 발
생 위험이 높아지는지 알아보고자 하였다. 실제 의무기록이 아닌 보험 청구 자료를 이용하였지만 뇌졸중의 경우 약 $83 \%$, 심근 경색증은 $76 \%$ 가 의무 기록과 일치한다는 결과가 보고된 바 있다. ${ }^{20)}$ 뇌졸중과 관련 있다고 알려진 연령, 고혈압, 당뇨, 만성 신장 질환과 같은 인자들을 보정한 이후에도 2002년에 서 2005년까지 돌발성 난청으로 진단받은 환자들의 뇌졸중 위험도가 대조군에 비해 의미 있게 높았다. 특히 뇌졸중의 유 형을 뇌경색과 같은 허혈성 뇌졸중과 뇌내출혈이나 지주막하 출혈과 같은 출혈성 뇌졸중으로 구분하여 분석한 결과, 허혈 성 뇌졸중의 위험도만 높아지는 것으로 나타났다. 돌발성 난 청 입원 환자의 경우 진단의 정확성은 더 높을 것으로 기대되 지만 대조군 또한 입원 환자로 추출되기 때문에 복합적인 질 환을 가지고 있을 가능성이 높아 결과 해석에 무리가 따를 수 있다. 따라서 추가적으로 돌발성 난청으로 진단받았지만 입원 하지 않고 외래 진료만 시행한 환자를 대조군과 비교 분석해 보았는데, 돌발성 난청군에서 출혈성 뇌졸중의 위험도가 대조 군에 비해 낮고 허혈성 뇌졸중의 위험도는 통계학적으로 유의 미하게 증가하였다. 입원하지 않은 돌발성 난청 환자의 경우 상대적으로 경증인 경우가 많을 수 있고, 돌발성 난청이라는 진단 코드의 부정확성을 고려하더라도 갑작스러운 청력의 저 하 증상은 뇌졸중과 관계가 있다고 해석할 수 있는 부분이다. 뇌졸중의 발생 위험을 가장 높이는 인자는 연령으로 나타났 다. 과거 연구에서도 45 세 이하보다 74세 이상의 돌발성 난청 환자에서 뇌졸중의 위험이 20 배 이상 증가한다고 보고하였고 이번 코호트 연구에서도 40 세 이하에서는 연령에 따른 뇌졸 중 위험도 증가가 보이지 않다가 40세 이상의 환자들에서 급 격히 뇌졸중 발생이 많아지며 70 세 이상에서 20 배 정도 위험 도가 높아지는 결과를 보였다. 따라서 고령의 돌발성 난청 환 자는 반드시 MRI와 같은 영상의학검사가 필요할 것으로 보인 다. 뇌졸중은 발생은 거주 지역 및 거주지의 도시화 정도와 관 련이 있다고 알려져 있고, ${ }^{21)}$ 본 연구에서 비도시 지역에 거주 하는 돌발성 난청 환자에서 1.2 배 정도 뇌졸중이 많았지만 외 래 환자만을 대상으로 분석해 보았을 때는 뇌졸중의 발생률과 연관 관계를 보이지 않았다. 고혈압, 당뇨병 등을 가지고 있는 환자는 뇌졸중의 위험이 높아지지만 만성 신장질환 환자는 예 상과 달리 뇌졸중의 위험을 높이지 않는 것으로 분석되었다.

이번 연구는 전 국민을 대상으로 하는 건강보험 자료와 이 를 대표할 수 있는 표본 코호트 자료를 활용하여 이루어졌고, 돌발성 난청 발생 이후 전향적인 뇌졸중 발생을 확인하였다. 100 만 명 이상의 표본을 이용하였기 때문에 우리나라 전체 인 구인 모집단에 대한 대표성을 확보할 수 있는 자료라고 할 수 있다. 하지만 의무기록이 아닌 건강보험청구기록을 바탕으로 이루어져 돌발성 난청, 뇌졸중의 유형 등 진단명의 정확성이 떨 
어질 수밖에 없으며, 특히 돌발성 난청의 경우 그 진단의 모호 성이 있어 3 개 주파수 이하, $30 \mathrm{~dB}$ 이하의 청력 감소도 실험 군에 포함되었을 가능성이 높다. 그리고 난청의 정도, 청력 회 복 여부, 흡연 여부를 알 수 없고 뇌졸중과 관련된 질환을 가 지고 있지만 보험 청구 내역에 없어 알 수 없는 경우도 있다. 또한 비급여 진료 내역이나 일반 의약품의 사용 등도 자료에 포함되어 있지 않다. 현재는 표본 코호트의 자료와 환자의 건 강검진 자료가 연결이 되어 있지 않지만 추후에 데이터를 통 합하여 분석할 수 있다면 더 정확도가 높아질 것으로 기대한 다. 본 연구는 돌발성 난청 진단을 받은 환자와 성향 점수 매 칭을 통해 $1: 5$ 로 대조군을 추출하였는데, 외래 환자의 경우 돌 발성 난청군에 비해 대조군은 전혀 이환된 질병이 없거나 의 료 기관 이용도가 떨어지는 경우가 있을 수 있고, 입원 환자의 경우 대조군이 다른 중증 질환을 가지고 있는 경우가 많아 질 수 있다는 표본 추출 편의(selection bias)가 존재한다. 돌발성 난청의 발생률은 매년 10만 명당 5 20명 정도로 알려져 있으 나 우리나라 표본 코호트 자료를 보면 10만 명당 80명 정도로 상당한 차이를 보이고 있다. 이는 일반적으로 통용되는 돌발 성 난청 환자의 진단 기준에 부합하지 않더라도 보험 청구를 위한 $\mathrm{KCI}$ 코드를 돌발성 난청(H912)으로 기록하는 경우가 많 기 때문으로 생각된다.

돌발성 난청의 원인으로서 혈관 장애는 주로 동맥의 협착 이나 폐쇄와 같은 허혈성 질환으로 설명되는데, 실제 보험 청 구 자료를 분석해 보았을 때 외래 진료를 받은 돌발성 난청 환자의 11 년간 추적관찰 결과, 출혈성 뇌졸중은 대조군보다 약 $32 \%$ 적게 나타나고 허혈성 뇌졸중은 약 $23 \%$ 많게 나타났 다. 앞으로 여러 기관의 입원 환자를 대상으로 한 전향적인 분석을 해본다면 더 의미 있는 결과를 얻을 수 있을 것으로 생각된다.

\section{REFERENCES}

1) Wilson WR, Byl FM, Laird N. The efficacy of steroids in the treatment of idiopathic sudden hearing loss. A double-blind clinical study. Arch Otolaryngol 1980;106(12):772-6.

2) Burton MJ, Harvey RJ. Sudden sensorineural hearing loss. In: Gleeson M, Browning GG, Burton MJ, Clarke R, Hibbert J, Jones NS, editors. Scott-Brown's Otolaryngology Head and Neck Surgery. 7th ed. London: Hodder Arnold;2008. p.3577-93.

3) Patzak MJ, Demuth K, Kehl R, Lindner A. [Sudden hearing loss as the leading symptom of an infarction of the left anterior inferior cerebellar artery]. HNO 2005;53(9):797-9.

4) Lee H. Audiovestibular loss in anterior inferior cerebellar artery territory infarction: a window to early detection? J Neurol Sci 2012; 313(1-2):153-9.
5) Kim JD, Son MS. National Health Insurance Statistical Yearbook. Seoul: Health Insurance Review and Assessment Service and National Health Insurance Service;2014.

6) Lin RJ, Krall R, Westerberg BD, Chadha NK, Chau JK. Systematic review and meta-analysis of the risk factors for sudden sensorineural hearing loss in adults. Laryngoscope 2012;122(3):624-35.

7) Wu CS, Yang TH, Lin HC, Sheu JJ, Chu D. Sudden sensorineural hearing loss associated with chronic periodontitis: a populationbased study. Otol Neurotol 2013;34(8):1380-4.

8) Oh HJ, Choi JY, Cho SI. The relationship of intra-annual distribution of sudden sensorineural hearing loss versus meteorological parameters. Korean J Otorhinolaryngol-Head Neck Surg 2014;57(12): 826-9.

9) Sheu JJ, Keller JJ, Chen YH, Wu CS, Lin HC. No increased risk of sudden sensorineural hearing loss following recent herpes zoster: a nationwide population-based study. Acta Otolaryngol 2012;132 (2):167-72.

10) Mun SK, Lee GH, Do YK, Hong YH. Sudden hearing loss caused by acute pontine infarction: reports of two cases. Korean J Otorhinolaryngol-Head Neck Surg 2008;51(7):650-4.

11) Kim YS, Choi SW, Woo YK, Jeon BS, Kim MH, Chi DH, et al. The clinical correlation between anterior inferior cerebellar artery and sudden sensorineural hearing loss. Korean J OtorhinolaryngolHead Neck Surg 2009;52(8):660-4

12) Ballesteros F, Alobid I, Tassies D, Reverter JC, Scharf RE, Guilemany $\mathrm{JM}$, et al. Is there an overlap between sudden neurosensorial hearing loss and cardiovascular risk factors? Audiol Neurootol 2009;14(3): $139-45$.

13) Kim JH, Roh KJ, Suh SH, Lee KY. Improvement of sudden bilateral hearing loss after vertebral artery stenting. J Neurointerv Surg 2016;8(3):e12.

14) Huang MH, Huang CC, Ryu SJ, Chu NS. Sudden bilateral hearing impairment in vertebrobasilar occlusive disease. Stroke 1993;24 (1):132-7.

15) Sauvaget E, Kici S, Petelle B, Kania R, Chabriat H, Herman P, et al. Vertebrobasilar occlusive disorders presenting as sudden sensorineural hearing loss. Laryngoscope 2004;114(2):327-32.

16) Lin HC, Chao PZ, Lee HC. Sudden sensorineural hearing loss increases the risk of stroke: a 5-year follow-up study. Stroke 2008; 39(10):2744-8.

17) Lee H, Sohn SI, Jung DK, Cho YW, Lim JG, Yi SD, et al. Sudden deafness and anterior inferior cerebellar artery infarction. Stroke 2002;33(12):2807-12.

18) Chang CF, Kuo YL, Chen SP, Wang MC, Liao WH, Tu TY, et al. Relationship between idiopathic sudden sensorineural hearing loss and subsequent stroke. Laryngoscope 2013;123(4):1011-5.

19) Chang SL, Hsieh CC, Tseng KS, Weng SF, Lin YS. Hypercholesterolemia is correlated with an increased risk of idiopathic sudden sensorineural hearing loss: a historical prospective cohort study. Ear Hear 2014; 35(2):256-61

20) Ryu SY, Park JK, Suh I, Jee SH, Park J, Kim CB, et al. The accuracy of myocardial infarction diagnosis in medical insurance claims. Korean Research Group for Cardiovascular Disease Prevention and Control. Yonsei Med J 2000;41(5):570-6.

21) Engström G, Jerntorp I, Pessah-Rasmussen H, Hedblad B, Berglund G, Janzon L. Geographic distribution of stroke incidence within an urban population: relations to socioeconomic circumstances and prevalence of cardiovascular risk factors. Stroke 2001;32(5):1098-103. 